\title{
نقد السياسة: الدولة والدين
}

المؤلف: برهان غليون

الناشر: المؤسسة العربية للدراسات والنشر، (بيروت، الطبعة الأولى 1991) 560 صفحة.

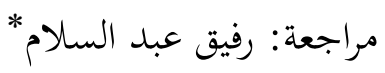

نقد السياسة: الدولة والدين من آخر الكتب التي صدرت للدكتور برهان غليون. ويعد هذا المؤلف بمثابة تتويج لكتاباته السابقة التي تناولت هذه الإشكالية مثل المسألة الطائفية ومشكلة الأقليات (1979) واغتيال العقل (1989) وبجتمع النخبة (1989) و الوعي الذاتي (1988) والتي تلاها المخنة الغربية:

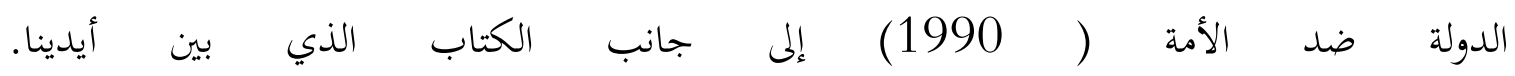

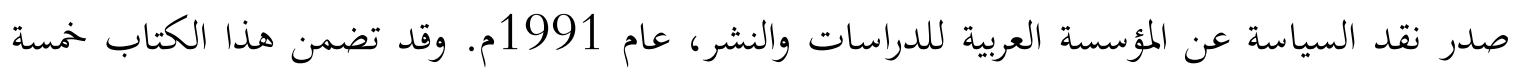
أقسام كبرى مهد لها المؤلف بمقدمة تأطيرية، كما تضمن كل قسم من الأقسام الخمسة فصولاً فرعية.

يمكن القول، من خلال ما يتم متابعته ورصده من كتابات الدكتور برهان غليون، إن هاجس الفكر الإسلامي وإحيائه بما يستجيب لحاجات هضنة العرب والمسلمين في وضعثم الحاضر قد مثل مثل معور اهتمام

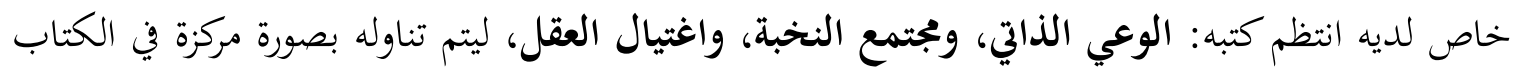

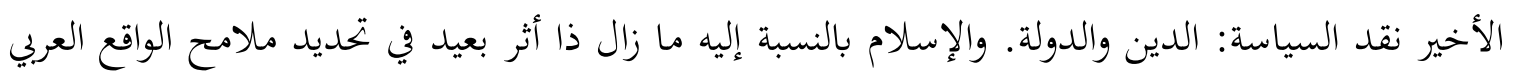

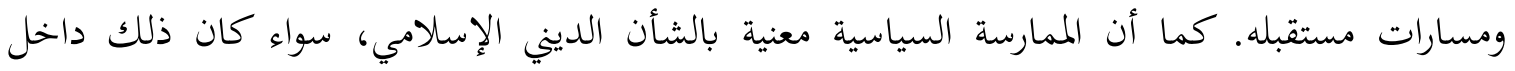
السلطة أو في المعارضة نظرا لما للإسلام من وظائف في تحديد أسس المشروعية وتوجيه القيم الثقافية والرمزية المهمة للفعل السياسي والاجتماعي. 
ونحن نعلم أن الإشكالية السياسية قد طرحت، من الناحية التاريخية، بحدة على الفكر العربي الإسلامي في

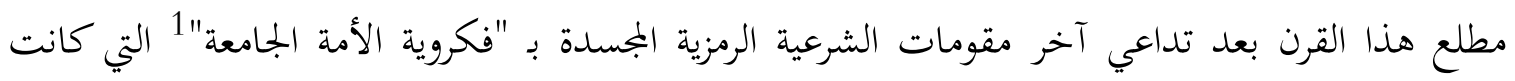

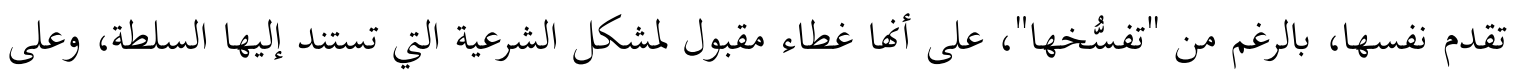

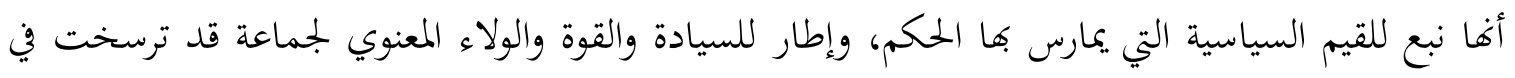

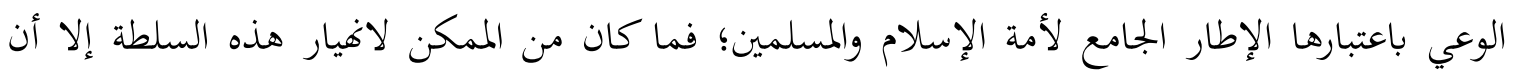

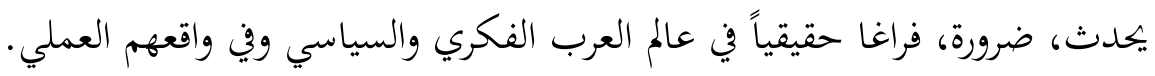

وقد مثل كتاب الشيخ الأزهري علي عبد الرازق، الإسلام وأصول الحكم، الذي جاء في غمرة تلك الحيرة

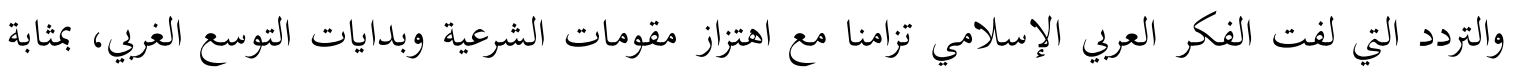

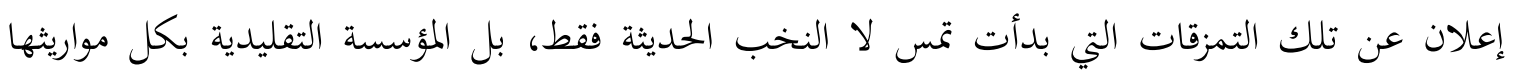

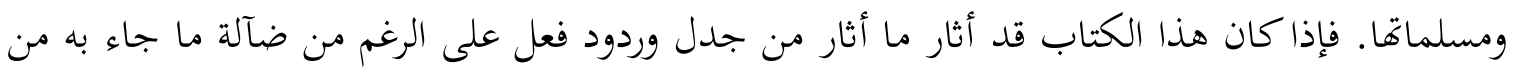

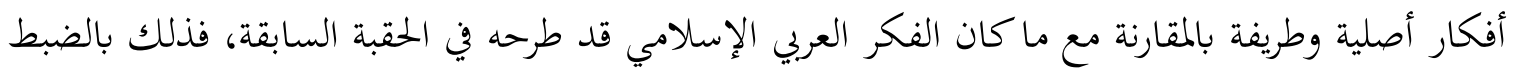

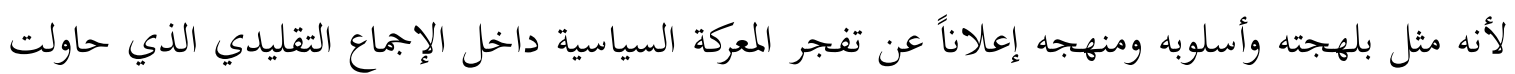

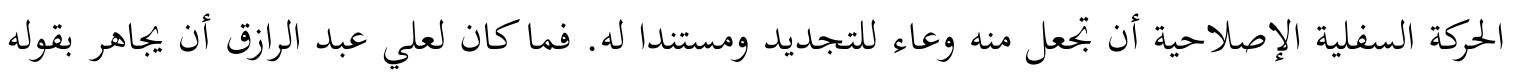
ذاك لو لم تتوفر له شروط تاريخية وثقافية و"أيديولوجية "كانت تسمح بتداول خطابه ولئ والإصغاء إليه.

وقد كان لتبلور رؤيتين متعارضتين إزاء إشكالية الدولة والشرعية: الأولى تسعى إلى أن تكون تواصلا مع

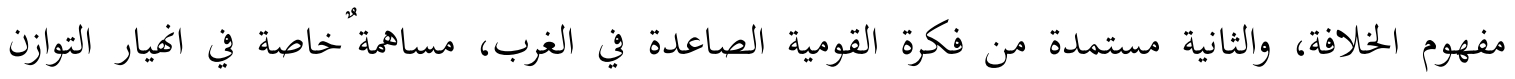

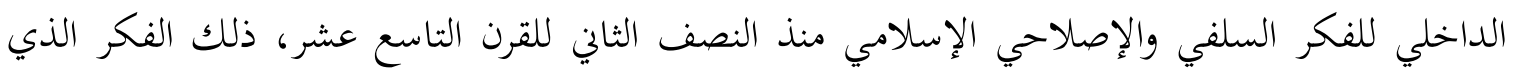

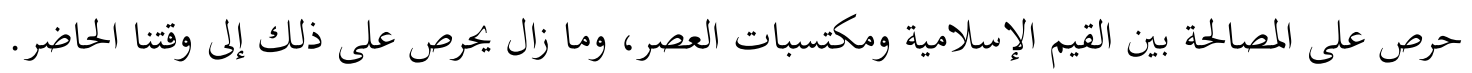

وما زالت إنكالية السلطة بكل توابعها ومحمولاتما مركز الإشكال في الوعي العربي الإسلامي، حتى إن حركة

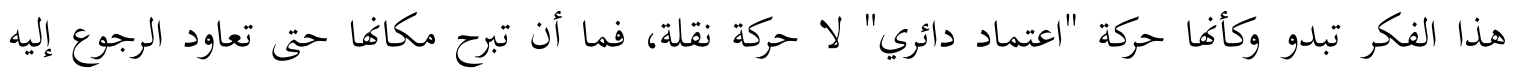

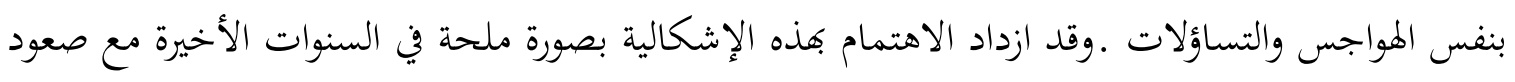

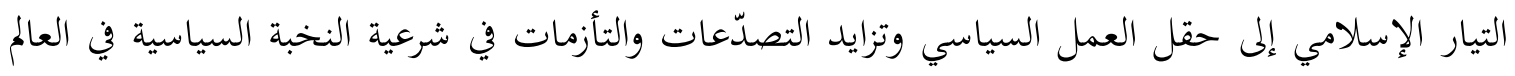

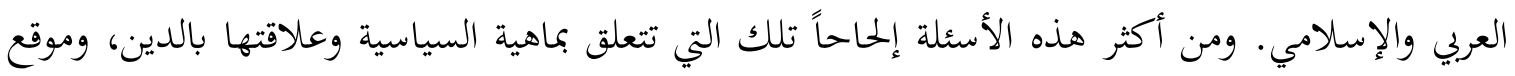

$$
\begin{array}{r}
1 \\
\text { (Episteme) }
\end{array}
$$




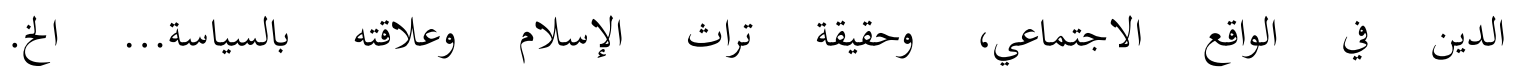
ويبدو أن الهم الأساسي لبرهان غليون يتركز حول كيفية ترتيب علاقة الإسلام بمجموع القيم الثقافية الموجّهة ولأوجه ممارسة السلطة واشتغالها بحيث يمكن قراءة هذا الكتاب حسب إثكالياته الكبرى وما تفرع عنها من قضايا وإحالات جانبية أخرى. ولمارسة

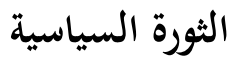

يقف الكاتب في بداية القسم الثاني من الكتاب عند ملامح التحول في الفكر السياسي الحديث من خلال

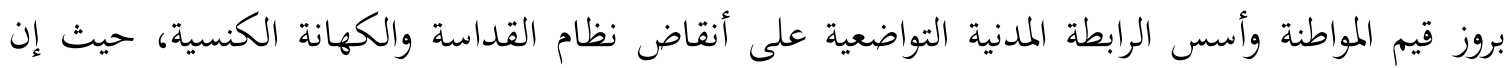

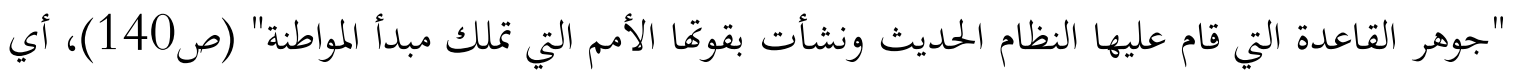
النظر إلى المشاركة الواعية للفرد الحر والمسؤول بوصفها قاعدة التضامن الوطني وبناء الرابطة العمومية. وتقوم

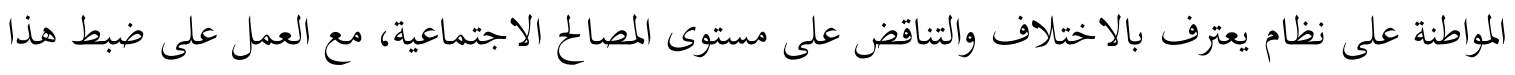

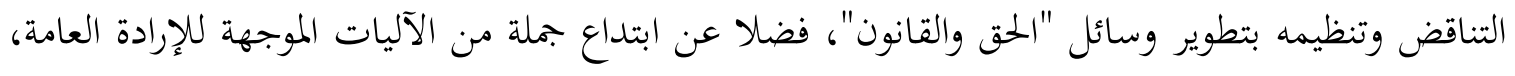
والمؤطرة لما. ويحدد غليون، السياق العام لتشكل هذه القيم السياسية الجديدة عبر التطور التاريخي للتجزئة الغربية وما رافقها من حركة منازعة ونبذ للإطلاقيات الكلية والكنسية، نشأت في الغرب وداخل المجتمع

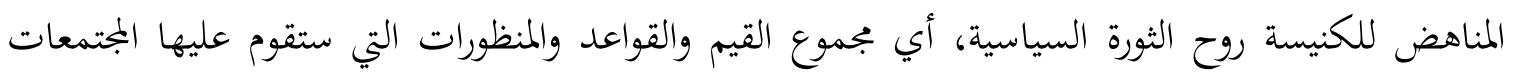
الغربية الحديثة (ص 164). وقد نشأت هذه الثورة السياسية -مثلما تدل على ذلك سياقاتها التاريخية

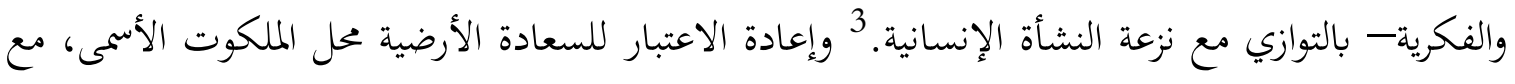
الابحاه نخو تقديس العقل والطبيعة.

وإذا كان الأمر كذلك بالنسبة للتجربة الغربية، فإن نظيرتا العربية الإسلامية قد كانت لها وتيرتما وسياقاتما

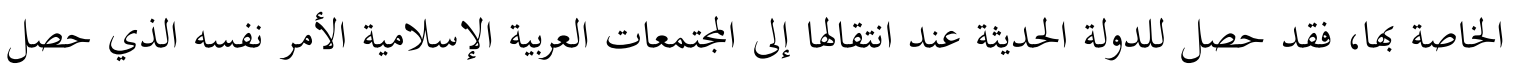

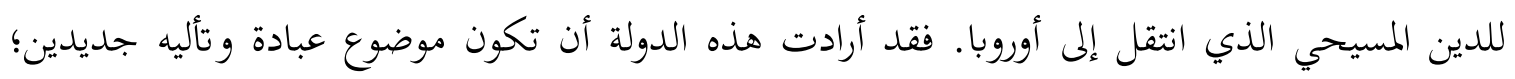

\footnotetext{
النزعة الإنسانية هي تيار عام عبر عن نفسه بصورة نسقية في الفلسفة الغربية الحديثة ابتداءً من القرن السابع عشر ـ ويتسم هذا التيار

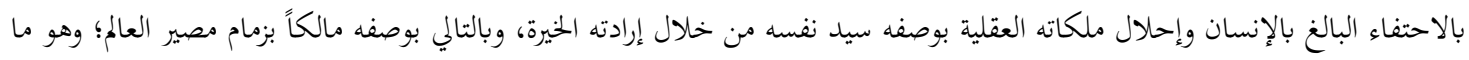

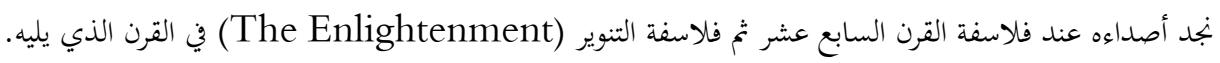


وهكذا، "بدل على أن تكون هذه الدولة مولدة للسيادة الوطنية وأن تتحول إلى منبع لقيم الحرية مثلما هو

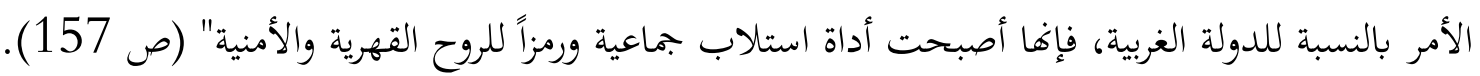
وبقدر ما جاءت السياسة المدنية في التجربة الغربية نفياً لسلطة الكنيسة والكهنوت الديني عامة، فقد كان

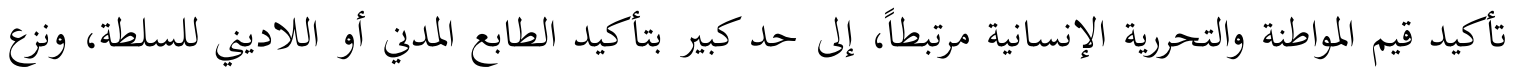
كل ألوان القداسة عنها. وبقدر ما كانت قيم التحرر الإنساني مرتبطة في مسار التاريخ العربي الإسلامي مئي

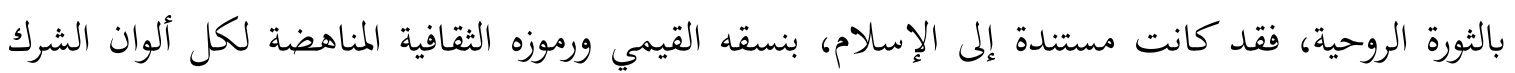
والمؤكدة على معاني التوحيد والمساواة.

ويؤكد غليون أن تَمُّلّ إطار الدولة الحلديثة وبجمل القيم السياسية الملازمة لها لم يكن نتيجة تطور طبيعي وذاتي في التجربة التاريخية العربية في العصر الحديث بقدر ما كان ذلك نتيجة لاهيار النظام القديم تحت تأثير الضغط المادي والعسكري والنفسي والثقافي للحضارة الغربية. فعلى أنقاض نظام السلطنة التقليدي المتفكك التك

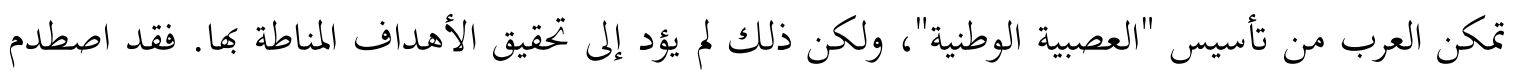

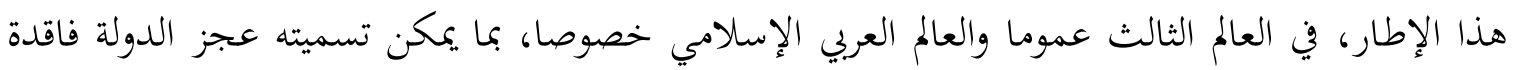

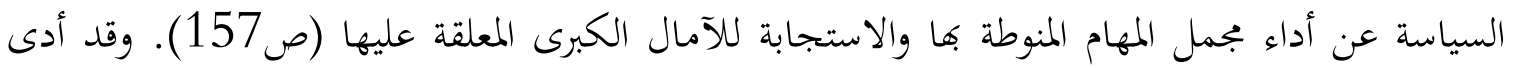

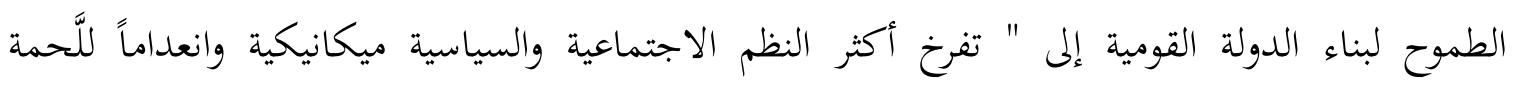

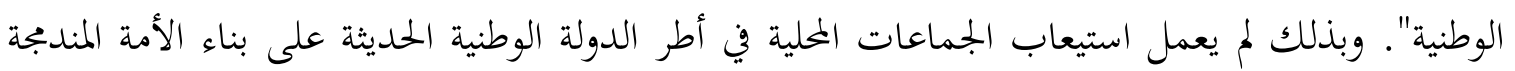

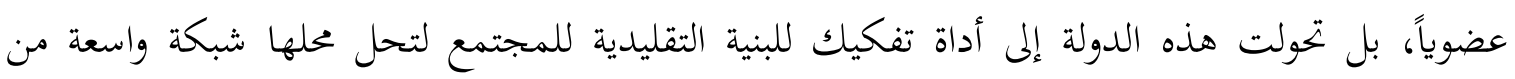
أدوات العنف والرقابة.

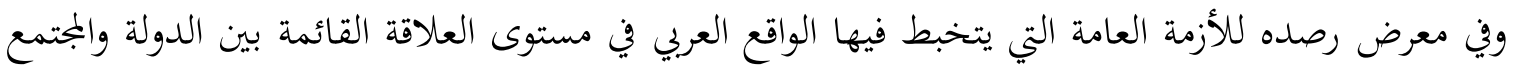
وغياب السلطة الثابتة ومقومات الشرعية، يحدد الدكتور غليون الآثار الاجتماعية الناجمة عن ذلك. فهو يرى

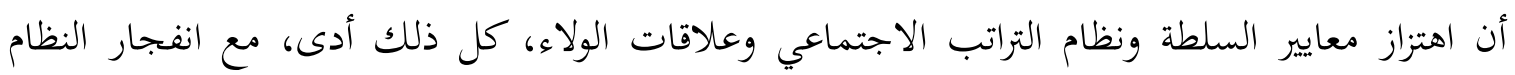

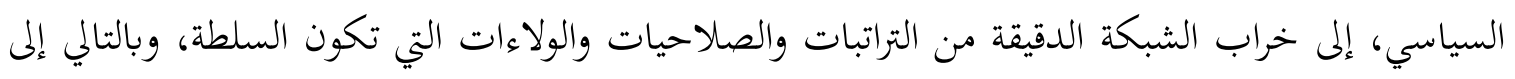

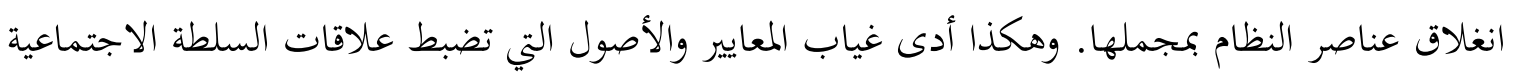
وتوزيع الصلاحيات، مثلا، إلى أن تتدخل السلطة السياسية في كل صغيرة وكبيرة من حياة الجماعات والأفراد

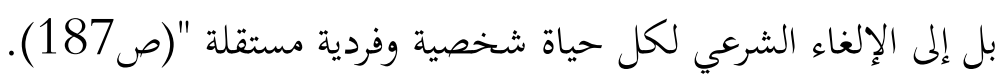


وهذا ما يفسر في الوقت نفسه ميل الدولة العربية المتزايد إلى استعمال العنف والتنكيل برعاياها بدل أن تكون راعية للسلم الأهلي والمصلحة العامة. "فبنفس الدرجة التي تبدو فيها الدولة عندنا على غاية القوة

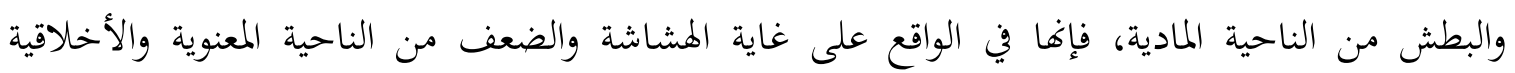

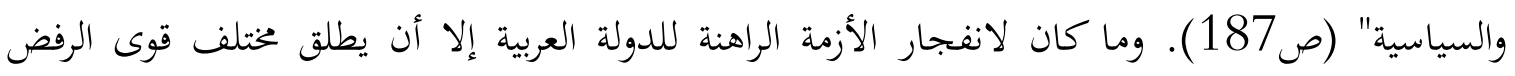

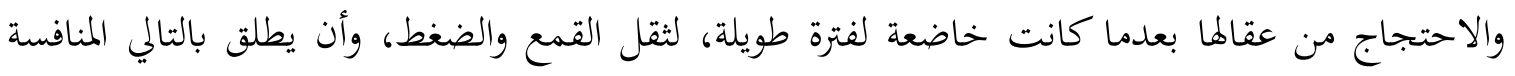

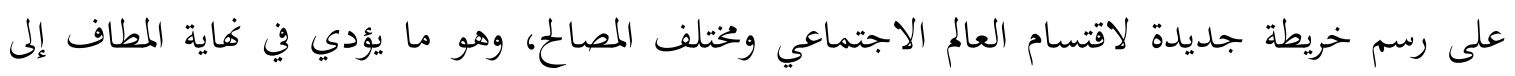
تخريب السياسة من أصلها بعدما يتم تحويلها إلى نوع من الرهان للسيطرة على جهاز الدولة باعتباره مركز تكثيف القوة والمصالح.

\section{نقد الدولة}

لقد أثار المد الإسلامي في العقود الأخيرة - ولا يزال يثير - لدى قطاع واسع من الباحثين تساؤلات متشعبة

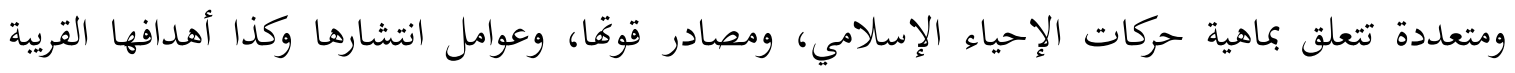
والبعيدة. ويبدو أن نمو الحركات الإسلامية جاء على غير تحليلات وتوقعات الإسيات العلوم الاجتماعية بمناهجها

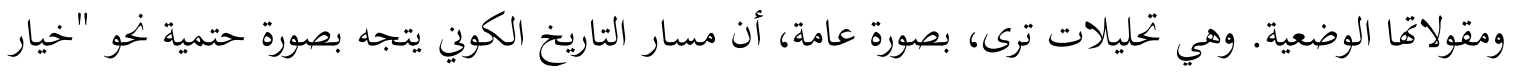

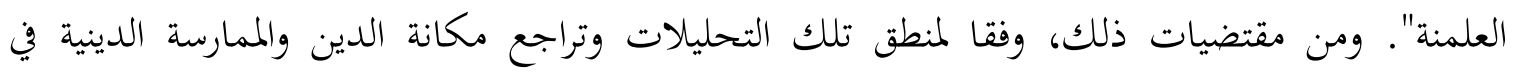

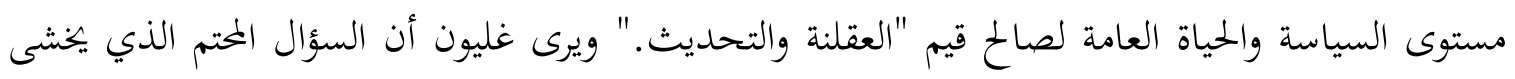
الكثيرون من عناصر النخبة العربية الجهر بطرحه هو الآتي: ما الذي يجعل الإسلاميين اليوم أقدر من غيرهم

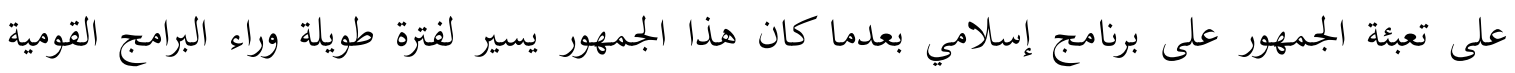
واليسارية؟ (197)

تكاد مختلف الطروحات الرائجة وسط القطاع الأوسع من النخبة العربية بتمع على الربط بين نمو الحركة

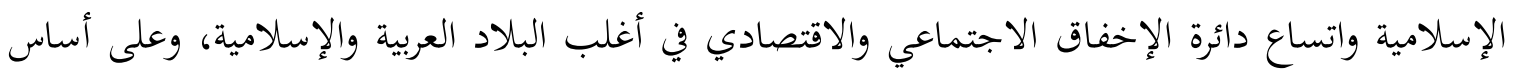

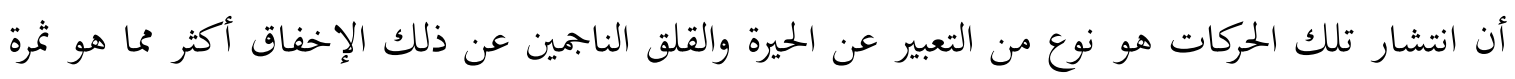

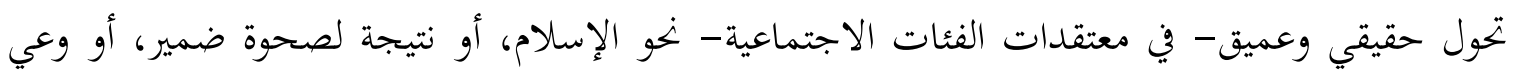
ديني. وقد ذهب فريق إلى الزعم بأن الحركات الإسلامية هي مجرد "ردة عقائدية وفكرية على عملية الحداثة 
وحركة التحول الحضاري، مصدرها استمرارية القيم القديمة والخوف من التحديث والمغامرة التحضيرية" (ص) (200)

من الواضح هنا أن القاسم المشترك بين مختلف هذه التفسيرات هو ربطها بين تنامي الحركة الإسلامية في

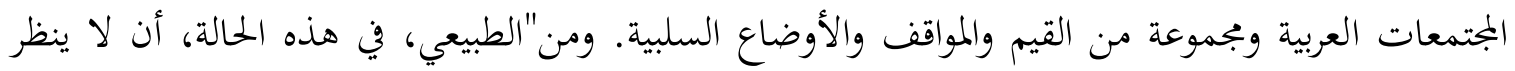

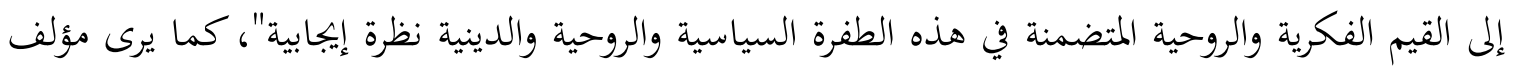

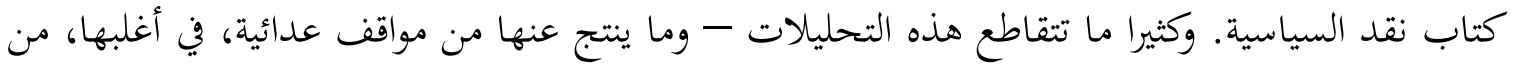

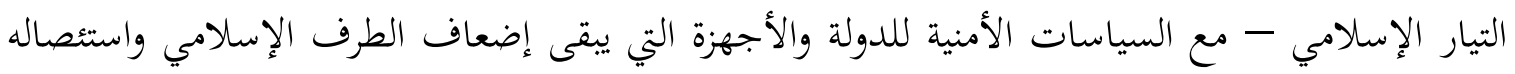
من الحياة السياسية والثقافية هدفها الأول وهاجسها الأكبر في الوقت نفسه.

إن حالة الصراع والاستقطاب حول الإسلام تتجاوز مستوى توزيع الثروة أو السلطة السياسية بالمعنى المباشر

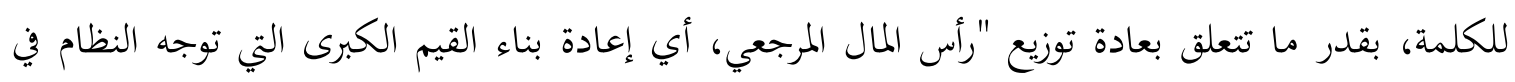

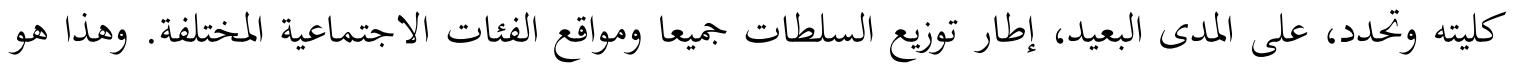

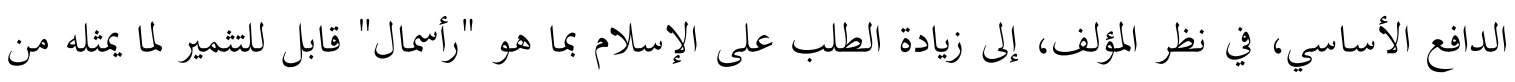

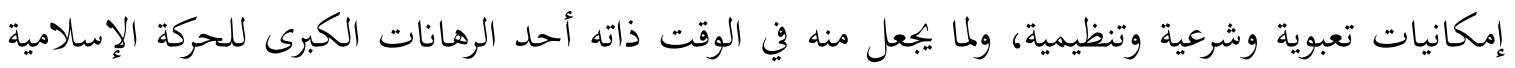

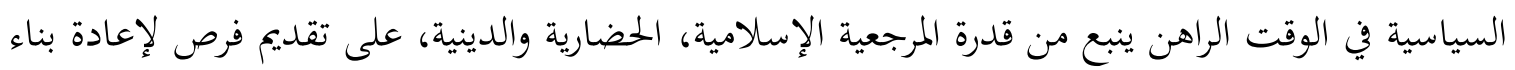

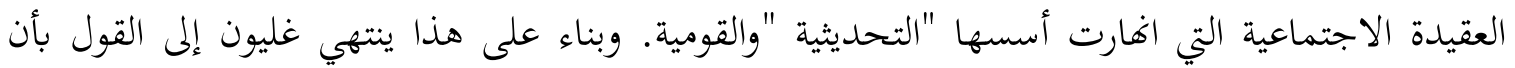
الحركة الإسلامية في العصر الحديث هي حاصل التقاء ثلاثة عوامل تاريخية كبرى:

1- حركة الإحياء الإسلامي بالمعنى الواسع للكلمة، أي بما هي استعادة بطيئة، ولكن دائمة ومستمرة، للثقافة الإسلامية "الكلاسيكية" وتمثل لقيمها. 2- تنامي المعارضة الإسلامية بموازاة أزمة الشرعية التي تعيشها الدولة والسياسة في الواقع العربي. ولا تنبع

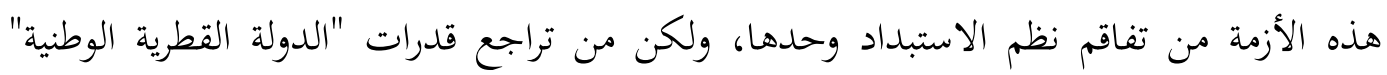

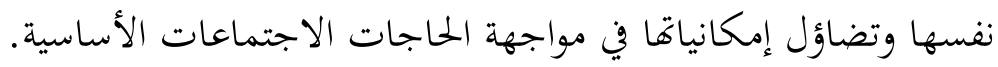

3- اتساع ظاهرة الاحتجاج الاجتماعي وشمولها نتيجة للأزمة الاقتصادية دون شكك، ونتيجة لتبدل طبيعة القوى الاجتماعية وتفاقم النفاوت بين النخبة والشعب وتنامي قيم المساواة والندية وما يرتبط

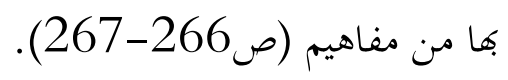


ويبرز برهان غليون في القسم الرابع من الكتاب السياقات العامة لنشأة العلمانية الغربية التي جاءت، في رأيه ردا على تحديات وحاجات واقعية وملحة عاشتها المجتمعات الغربية. وقد طرحت العلمانية بمعنيين اثنين:

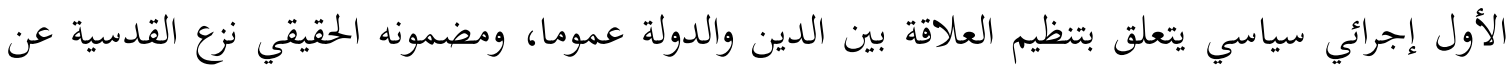

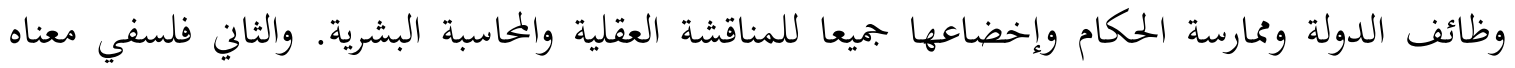
"إدارة الرأسمال الفكري, وتنظيم العلاقات داخل العقل نفسه بين مصادر القيم والرموز المختلفة, القديمة

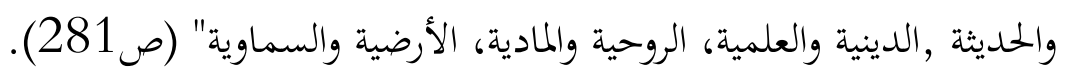

وينبه الكاتب إلى أن التجربة التاريخية العربية لم تحتج الى الحل العلماني لأنه لم يكن يعبر لها عن حاجة أصيلة

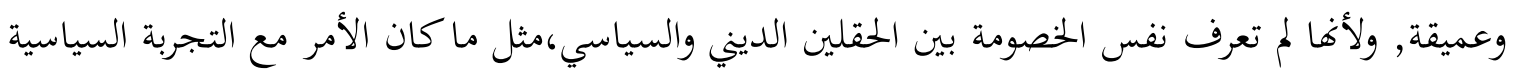
الغربية .ولذلك لم يحتج الأمر هنا الى ظهور العلمانية نظرية لتحرير الدولة من سلطة الكنيسة ولاستقلال

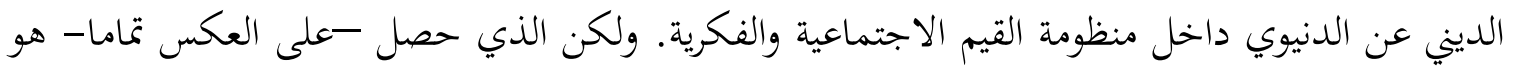

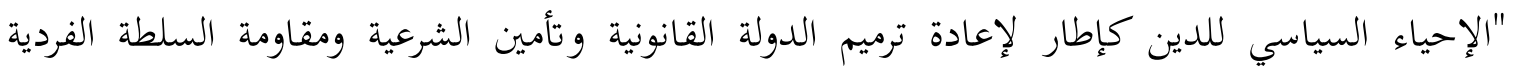

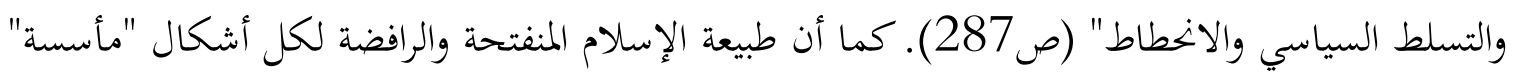

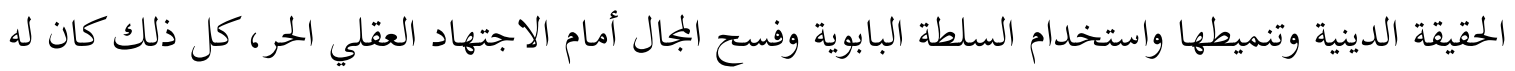
الفضل في إضفاء الطابع المدني على السلطة، واستبعاد كل أشكال الكهانة والقداسة عن الحكم.

وعليه، فبقدر ما كانت العلمانية الغربية "اكتشافا إيجابيا خطيرا ومبدعاً بما أعطته من فرص سياسية لفك

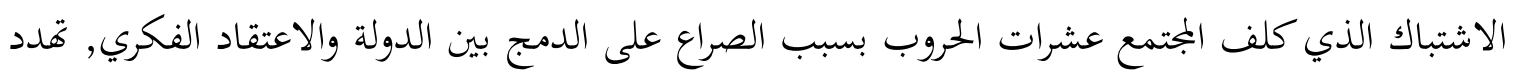
العلمانية المتحولة إلى دين وعقيدة بتخريب الوعي السياسي وتعميق الخلط بين سلطة الدولة وبين مذهب

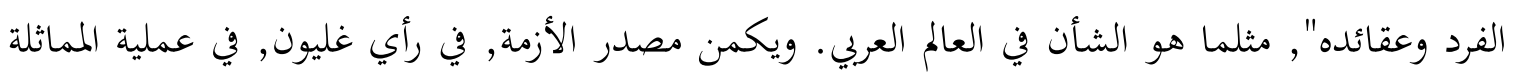

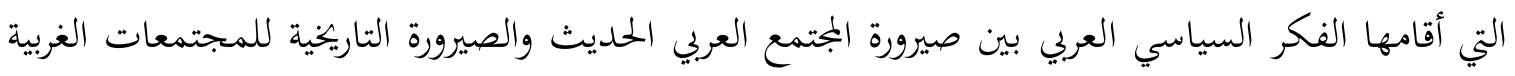
المسيحية الوسيطة, في غياب الوعي بمستوى الاختلاف والخصوصية. ذلك "أن أصل المشكلة عندنا وهي

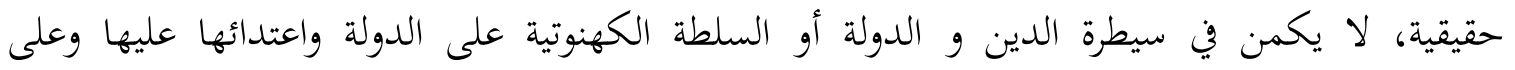
اختصاصاهما، وإنما تنبع -بالعكس تماما- من مصادرة الدولة للدين وسيطرقا عليه واحتوائه وتوظيفه في

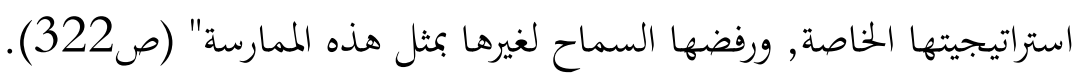

ولذلك يرى غليون أن أساس المشكلة لا يمكن في المعتقد الديني ولا في عملية المزاوجة بين الديني والسياسي،

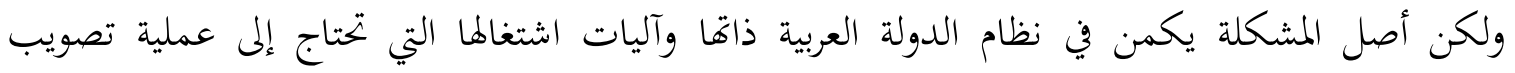


وإصلاح جذريين .وعلى هذا الأساس "لن يكون هناك أي أمل في تجاوز السلطة الأتوقراطية والشرور النابعة

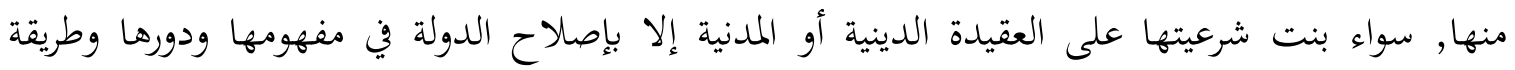

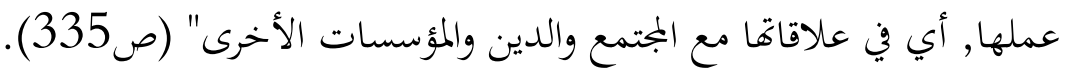

وخلاصة الأمر أنه إذا كانت المجتمعات الغربية المسيحية التي أفرزت الحل العلماني قد عانت من سيطرة رجال

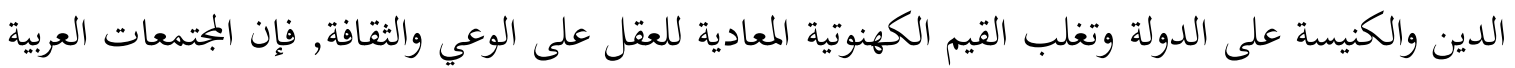
الإسلامية قد رزحت لفترة طويلة تحت نظام سيطرة رجال الدولة على السلطة المطلقة وغلبة الروح الذرائعية

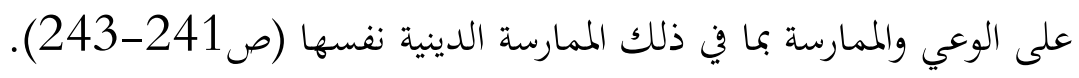

\section{السياسة والشريعة}

وفي القسم الأخير يتناول غليون إشكالية الاستقطاب السياسي والثقافي -التي تشق الساحة العبية

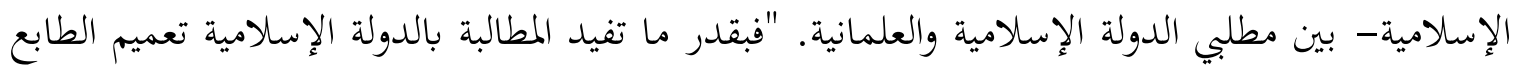

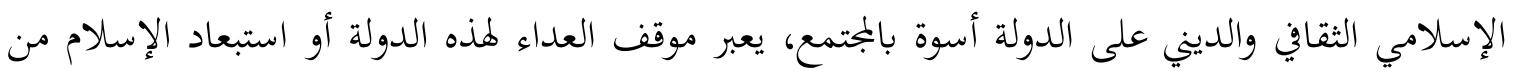

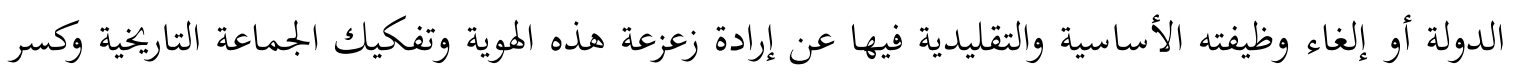

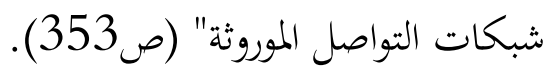

وإذن فالأمر هنا يتعلق أساسا، بقضية المرجعية وأسس الشرعية الثقافية والسياسية. فبسبب ما للإسلام من

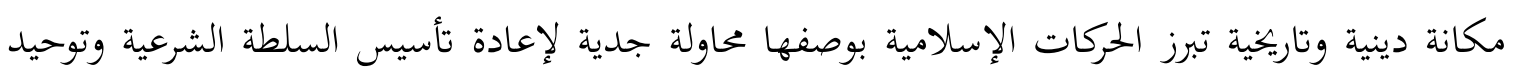

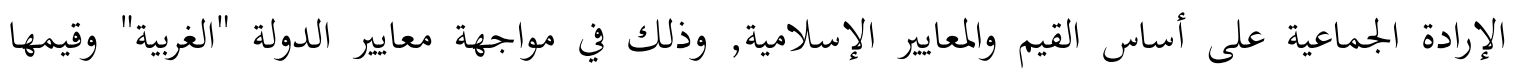

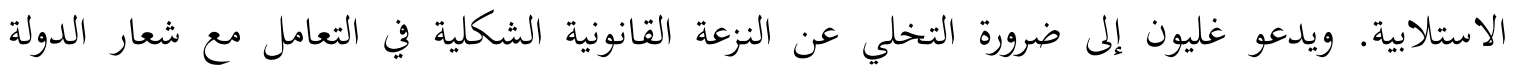

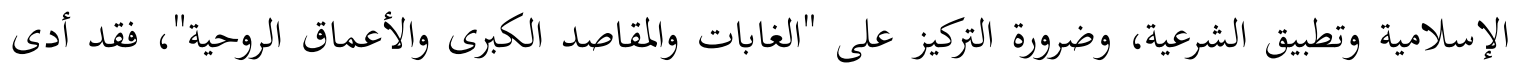
تسرب مفهوم القانون الحديث والوضعي إلى الفكر الديني نفسه إلى مطابقة مفهوم الشريعة غائيا مع القانون وتحويل الإسلام إلى ما يشبه المدونة المادية للأماكن والنصوص المهرك المحدة التي تنظم حياة مجتمع ما من الوجهة

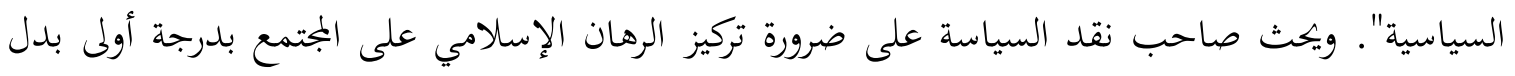

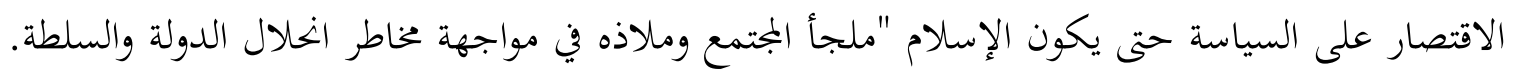


وهو لا يمكن أن ينجح في بناء سلطة أو دولة إلا إذا نجح مسبقاً في بناء المجتمع: أخلاقيته، روحه، وحدته،

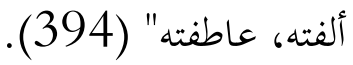

إن المشلكة الحقيقة التي يطرحها العمل الإسلامي لا تكمن في نزوعه إلى استثمار القيم الدينية في العلم

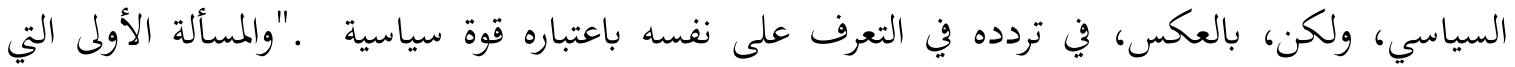

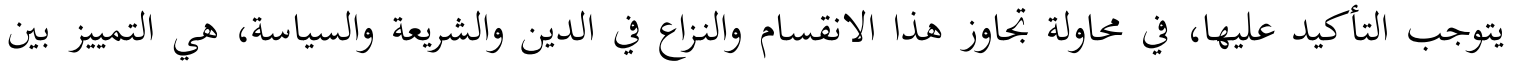
الإسلام كجماعة ودين من جهة والحركة الإسلامية كفريق إسلامي أو كاجتهاد من بين اجتهادات إسلامية

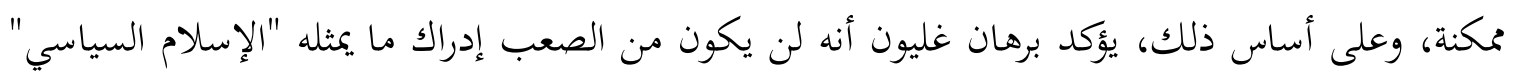

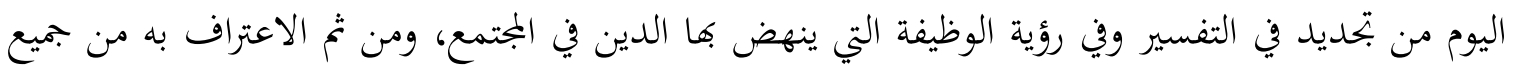
المسلمين بوصفه مدرسة إسلامية أصيلة.

وفي الأخير يدعو المؤلف إلى ضرورة إيجاد نوع من التسوية التاريخية التي تضع حداً لحالة التمزق والتنابذ التي

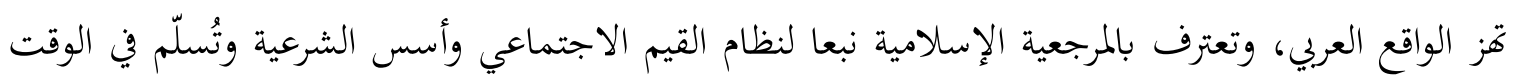

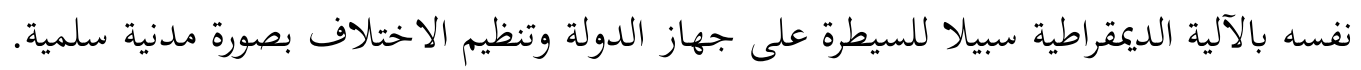

\section{الإشكالية المستقرة}

هكذا، يتضح من العرض السابق، كيف صاغ غليون الطابع الإشكالي لعلاقة الدين بالسياسة والدولة. وهي

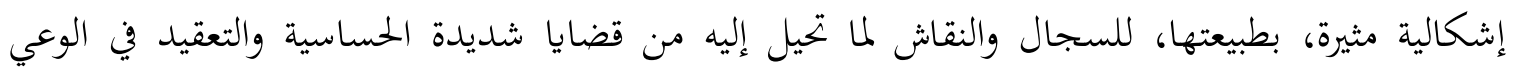

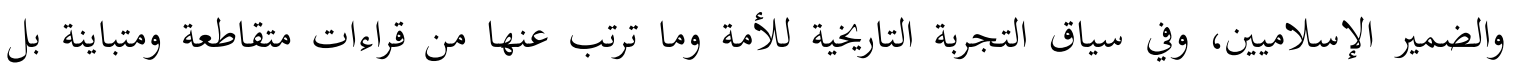

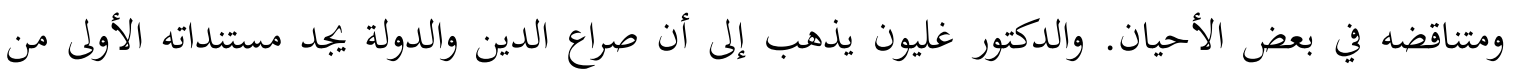

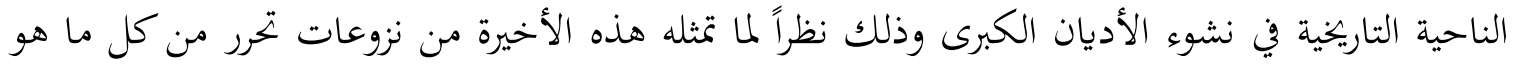

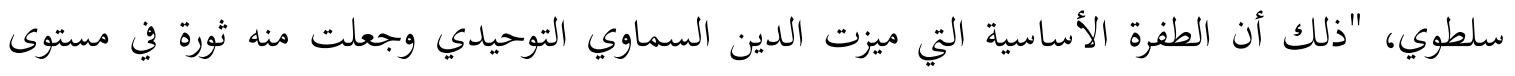

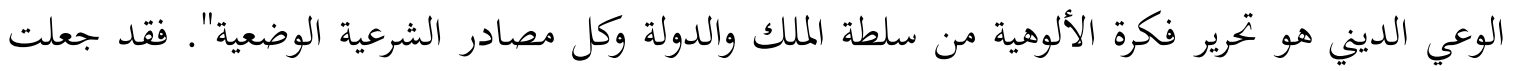

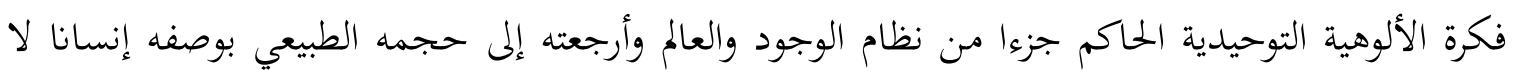

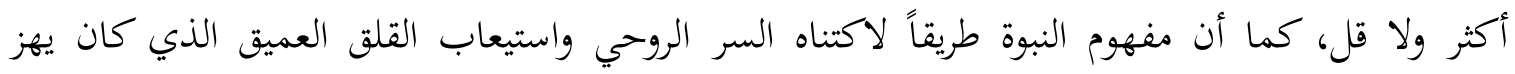
شعوب الحضارات القديمة قد ساهم في تقويض مرتكزات النظام الديني القديم القائم على منازع العبودية 
وتقديس الملك و تأليهه. وفي هذا الإطار يؤكد غليون أن ما هو مشترك بين الأديان الثلاثة الكبرى (اليهودية،

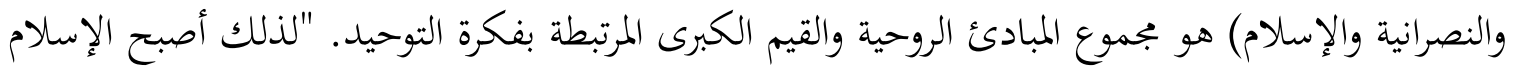
مستقرا للروح العالمية ومركز تركيب حضاري عالمي بامتياز، بقدر ما أتاحت عقيدته نفسها توحيد الحقيقة

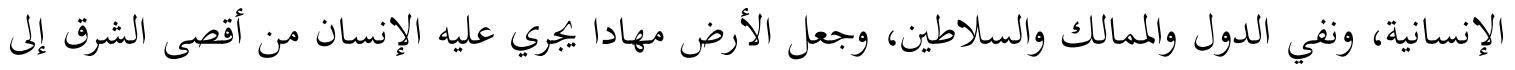

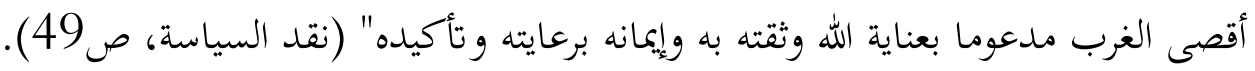

أما فيما يتعلق بإشكالية السلطة في الإسلام عموماً أو ما اصطلح على تسميته بالحلافة، فإنه يذهب إلى

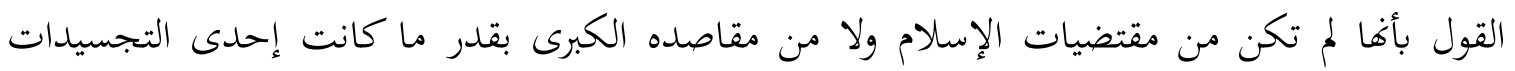

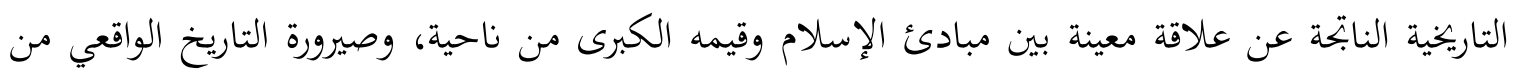

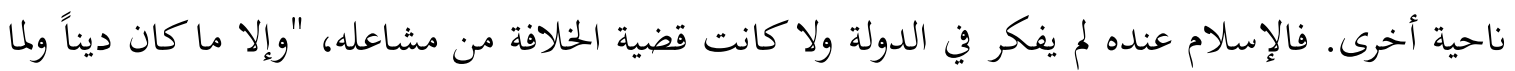

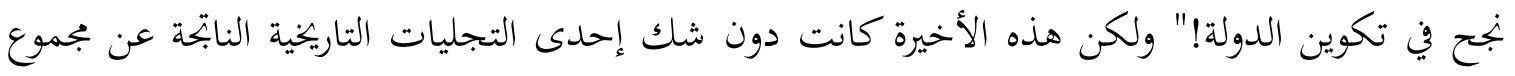

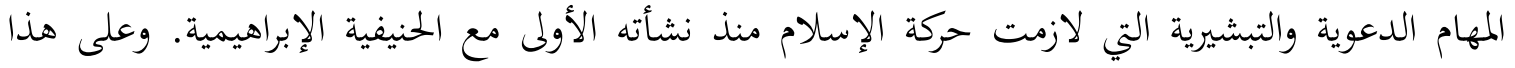

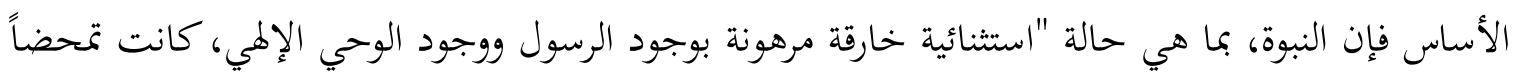

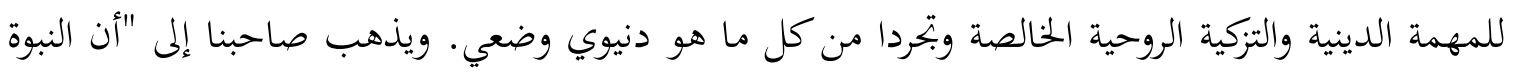
لا تقود المؤمنين إلى الدولة ولكنها تدعوهم إلى الحلاص من مخاطر الدولة والدنيا معا بما تنذرهم له من مهام

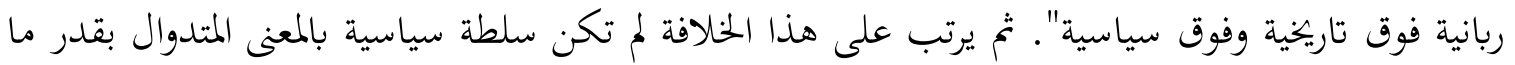

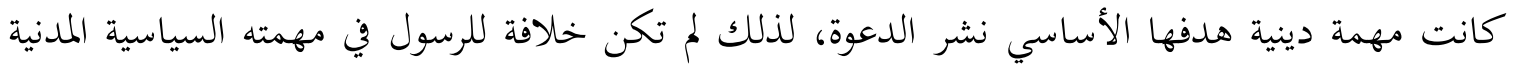
بقدر ما كانت خلافةً له في مهامه الروحية والدعوية.

وهذا يعني أن الدولة تحديدا لم تتأسس، في رأي الدكتور غليون، من داخل الإسلام بحسب سياقه العام أو بحسب بتسيدات التجربة النبوية بقدر ما كانت على تخوم الإسلام وأطرافه بفعل تطورات تاريخية لاحقة.

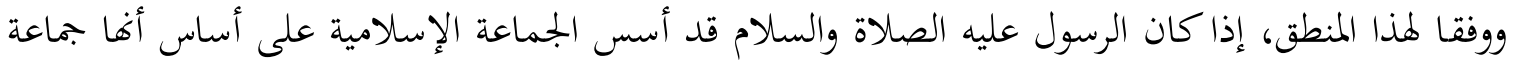
دينية، فقد دفعت الفتوح إلى تأسيسها جماعة سياسية أيضاً، أي أضطرةا إلى أن تعيد بناء سولكها من من إنساء منظور حاجاتا الاستراتيجية الكبرى. ومنذ ولاية الخليفة الثالث عثمان رضي الله عنه سيتم التحول في

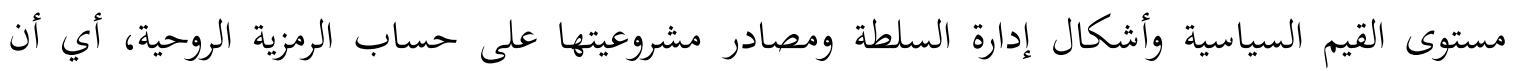

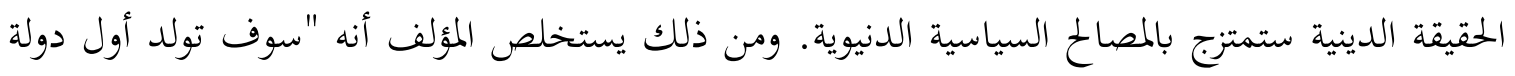
إسلامية فعلية ويمثل عهده (أي عهد عثمان)، كما مثل في موته، حلقة الانتقال والقطيعة معاً في حقيقة القئه

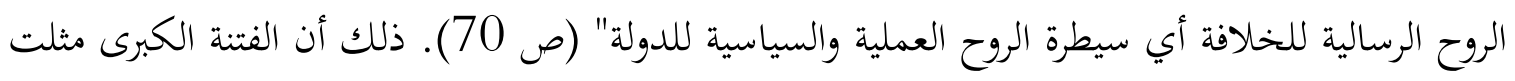


مظهرا معبرا عن بداية اختلال التوازن بين معطيات الحقيقة الدينية وموجهاهًا القيمية من ناحية والحقيقة

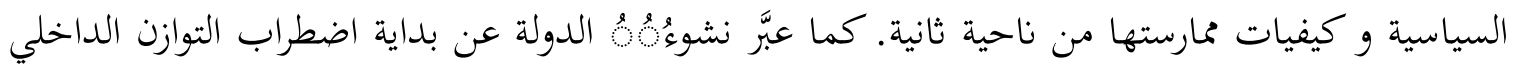
للدعوة والجماعية الداعية، لأن النبوة ليست حالة دائمة ولا عادية، ولا يمكن أن تكون إلا محطة استثنائية في التاريخ، محطة أنتجت أمة ورمتها في لجة الصراع المصيري لتمحص إرادها وقدرةها على الاستمرار.

وبهذا المعنى ينتهي الأستاذ غليون إلى المصادرة على حقيقة مفادها التخارج بين الحقيقة الدينية والحقيقة

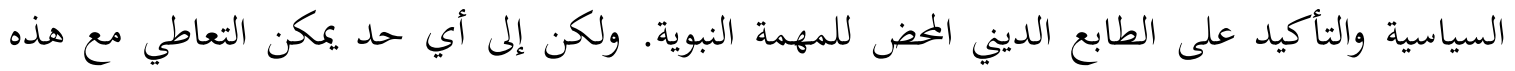
الحقيقة والتسليم . ما؟

يبدو أن هذه القراءة التي يقدمها صاحب كتاب نقد السياسة تثير عددا من الإشكاليات والإحراجات التي يصعب التغلب عليها، سواء كان ذلك من ناحية استقراء النص القرآني والنبوي بحسب مقتضياته أو إن

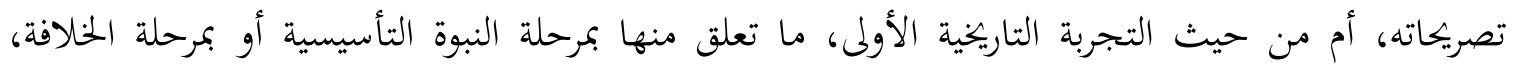
وكذلك من جهة المنظور والتصور العام للإسلام ومستندات العقيدة نفسها.

صحيح أن الإسلام لم يقدم نظرية جاهزة في الدولة ولم يحدد نمطا واحدا لأشكال ممارسة السلطة، ولم يكن

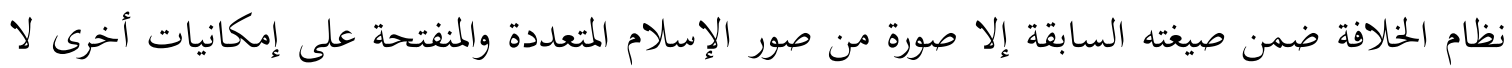

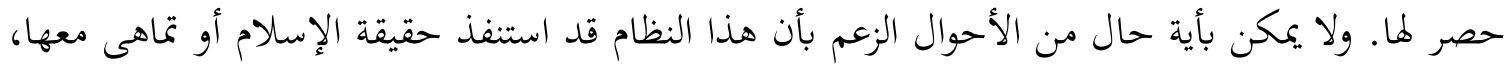

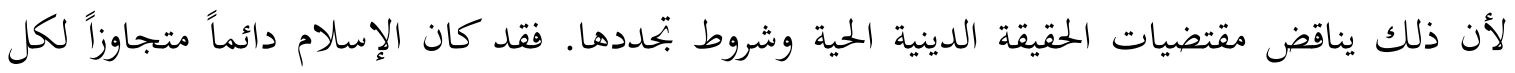

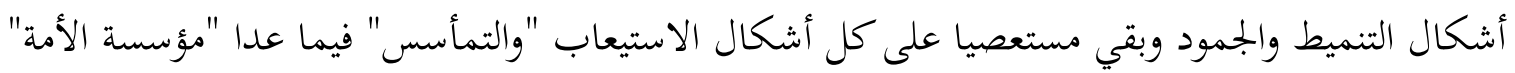
التي شرع استخلافها لتحيى وتمتد في رحاب النص وفي توحد معه وبه. ولعل هذا هو المسوغ الوحيد

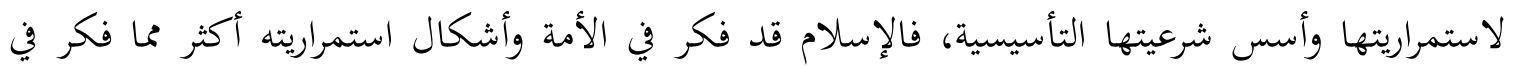

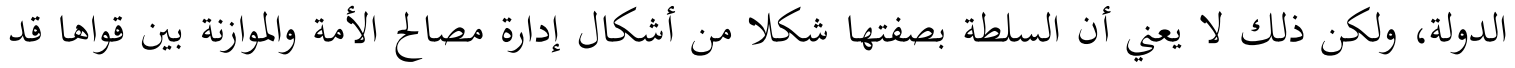
كانت خارج دائرة اهتمام الإسلام طالما أن ذلك يعد من مستلزمات التفكير في الأمة ذاتما ورعاية مصالحها

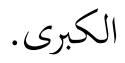

فعلى عكس غليون، يذهب رضوان السيد، مثلا إلى القول بأن مفهوم الخلافة يرتبط ارتباطاً وثيقاً بمعاني القيادة الدينية والسياسية ويتقاطع معهما، وهو ما يتضمنه مفهوم الاستخلاف الشمولي كما يطرحه القرآن. وهذه هي المسوّغات الأساسية لتسمية المسلمين مؤسسة الحكم بعد الرسول عليه الصلاة والسلام بالخلافة؛

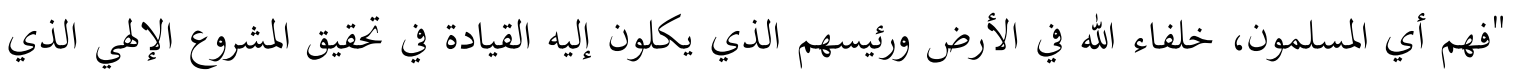


نذرهم الله له هو الخليفة". 4 ونخن نعلم من الناحية التاريخية أن الرسول صلى الله عليه وسلم قد قام بعمل

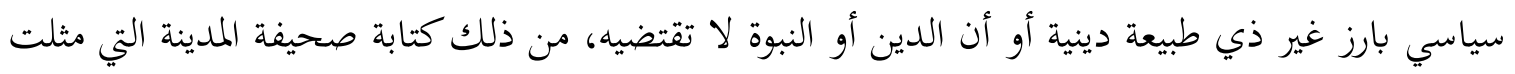

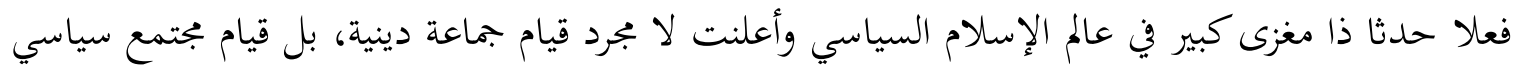

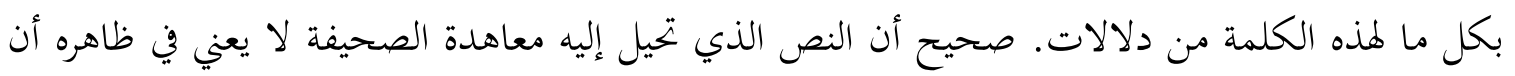

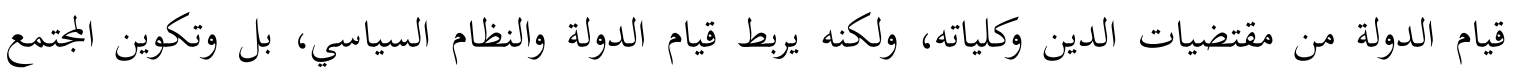
السياسي نفسه، بالمعهد المديني من دعوة الرسول عليه السلام. هذا ويصعب كذلك ولك أن نتصور خلافة أبي

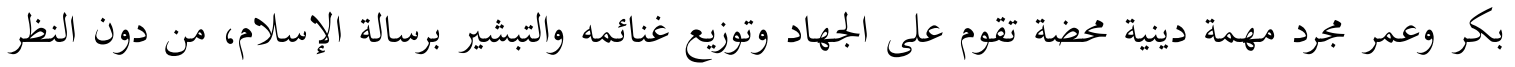

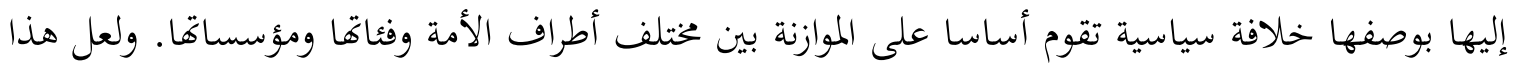
هو مبعث نجاح القيادة السياسية للخليفة الثاني عمر بن الخطاب الذي قام، في خلافته الطويلة نسبيا (عشر

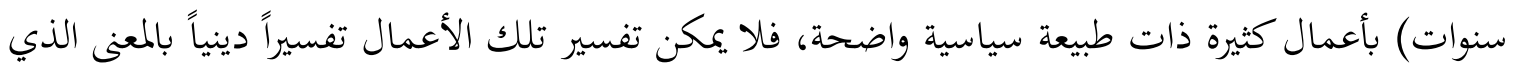

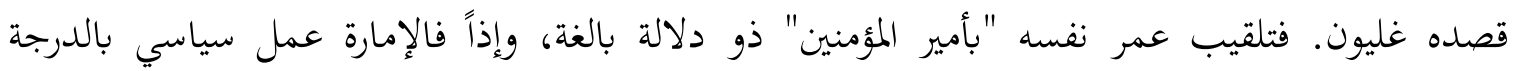

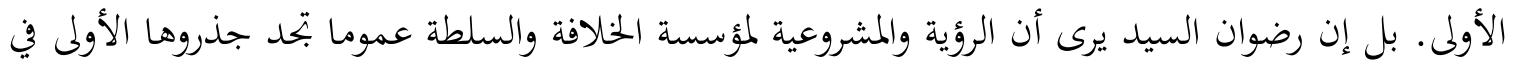
السياق العام لآيات النص القرآين التي فهم المسلمون الأوائل من منطوقها وإحالاتها أها تتضمن مفاهيم

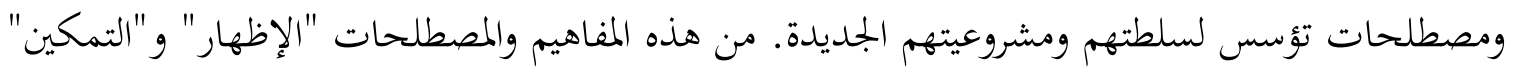
و "الاستخلاف" و"التوريث" و "الوعد"؛ وهي كلها معان تحيل إلى القول بالأمة المستخلفة عن النبي

$$
\text { المستخلف عن النبوات السابقة. }
$$

ويمكن القول إن النبوة ذاتا، على الرغم من طابعها الروحي الخارق القائم على تلقي الوحي المتعالي، تؤكد إلى حد كبير هذا التداخل بين الحقيقة الدينية والحقيقة السياسية منذ المرحلة الثانية للنبوة، أي الفترة المدنية. ذلك

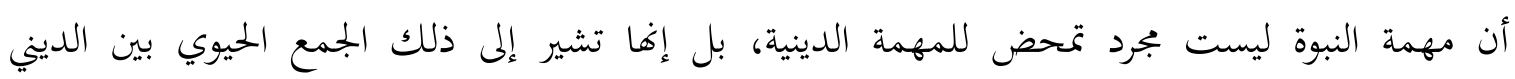

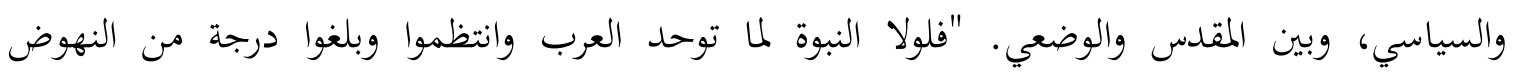

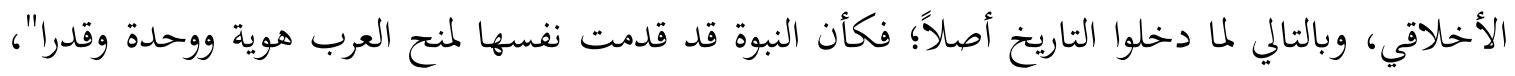
كما يؤكد ذلك بحق هشام جعيط.

بل إن الحركات الاجتماعية السياسية التي أنتجها عالم الإسلام السياسي كانت، في مصادر مشروعيتها وفي

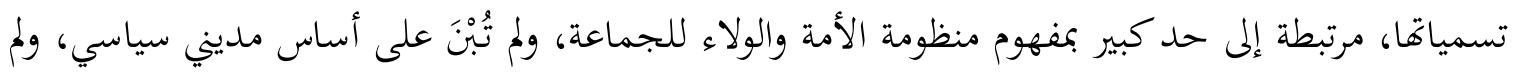

$$
\begin{aligned}
& 4
\end{aligned}
$$

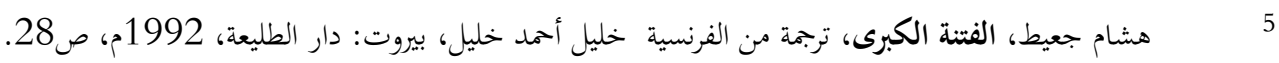


تسمّ نفسها على أساس جغرافي موضعي أو على أساس انتماء "عصبوي طبيعي" مثلما كان الأمر بالنسبة

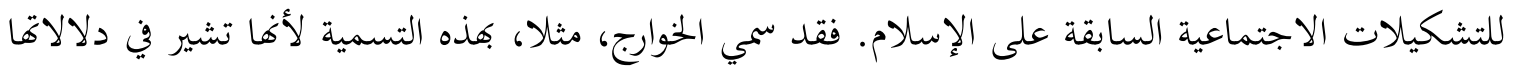

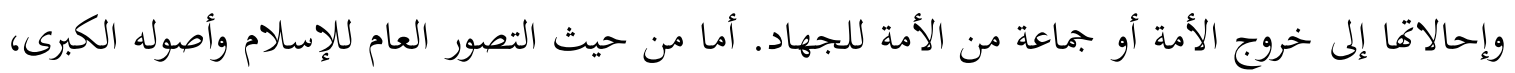

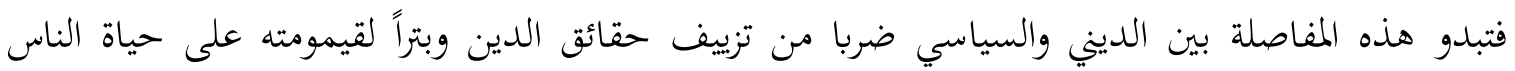

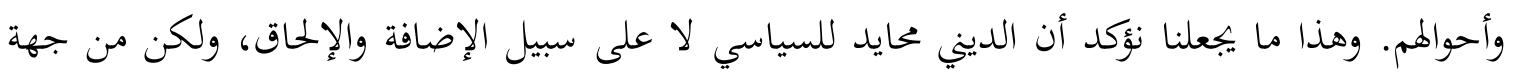
الكينونة وأصل التكوين. ونخن نعلم أن كل مسلك حينما يخرج عن حالته العينية والشخصية ويتحول إلى لئل

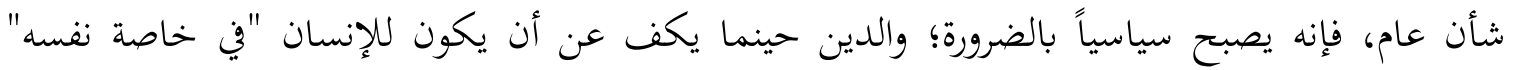
ويصبح شأناً للجماعة، فإنه يستحيل إلى فعل سياسي ضرورة.

بقي أن نشير إلى أن غليون يلفت الانتباه في آخر كتابه إلى حقيقة لازمت الصيرورة التاريخية للفكر السياسي

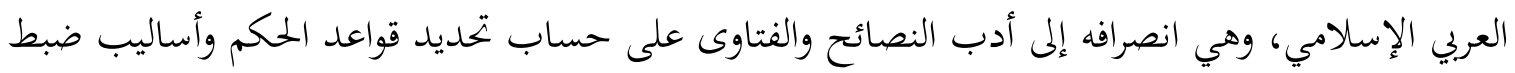

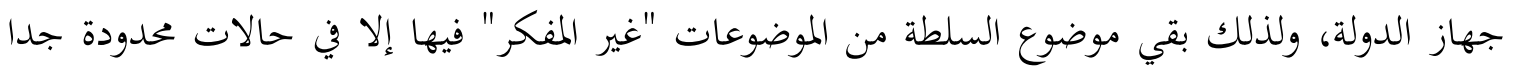
من الفكر السياسي العربي الإسلامي. وبسبب ذلك افتقد المجتمع الإسلامي القدرة على السيطرة عليها

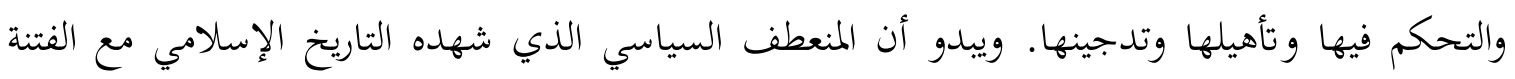

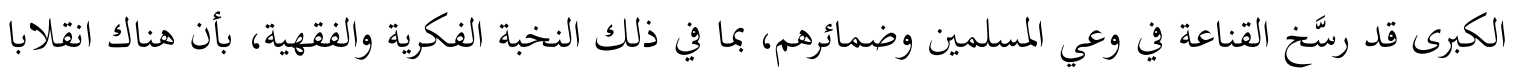

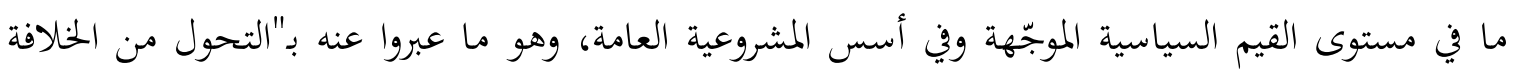

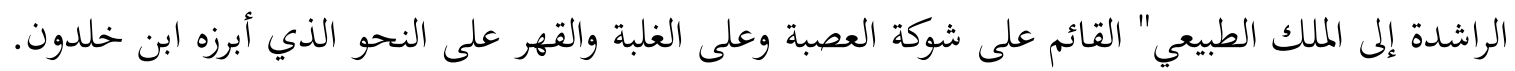

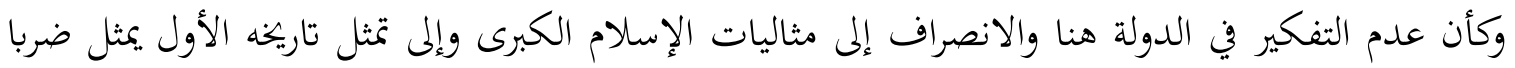
من التفلت من الدولة القاهرة وعدم اعتراف بشرعية حكمها. 